\title{
The Effect of Tartaric Acid New Derivatives AGAINST the Multidrug Resistant Opportunistic Pathogenic Soil Strains of Pseudomonas Fluorescens
}

\author{
Bella G. Babayan", 2*, Aram R. Mikaelyan², Nona L. Asatryan², Samvel A. Bagdasaryan', \\ Marina A. Melkumyan ${ }^{1}$ \\ 1“Armbiotechnology" Scientific and Production Centre (SPC), National Academy of Sciences (NAS), Republic \\ of Armenia (RA), Republic of Armenia. \\ ${ }^{2}$ National Polytechnic University of Armenia (NPUA), Republic of Armenia
}

\begin{abstract}
.
The quantity of multidrug resistant bacteria, including phytopathogenic and pathogenic for human organism is increased caused by enlarging of antibiotic usage by mankind. And this problem is more makeable in developing countries, because of uncontrolled usage of antimicrobial preparations including the antibiotics led to new multidrug resistant bacteria selection and forming in hospitals and agricultural objects. But the initial source of resistant bacteria is soil. Thus, the search of natural, ecologically safe effective preparations against them is very important for medicine and ecology. One of the directions of searching of alternatives instead the antibiotics while the therapy of multidrug resistant infections is the usage if semisynthetic antimicrobial compounds with enlarged spectrum of properties. Tartaric acid is well-known antibacterial preservative food additive. That is why, the main aim of current research was the research of antibacterial effect of first time synthesized in our laboratory 4 derivatives of it - benzylimide, cyclohexylimide, benzyl mono amino salt and Cyclohexyl amino salt of tartaric acid on different strains of well-known by the highly adaptive metabolism - Pseudomonas fluorescens from The National Collection of Microorganisms of Microbe Depository Centre, "Armbiotechnology" Scientific \& Production Center, Republic of Armenia. During the experiments it was shown that all compounds were are more effective than tartaric acid and tartrates. For the resistant representatives, which were in the minority, the absence of possibility to transfer the resistance to other Gram-negative bacteria was shown. Besides, there was showed the possibility of these compounds biodegradation by some Pseudomonas representatives.
\end{abstract}

Keywords: Pseudomonas fluorescens, multidrug resistance, tartaric acid derivatives, biodegradation. 


\section{Introduction}

Pseudomonas are very common well-researched Gram-negative bacteria with highly adaptive metabolism. They include opportunistic pathogens of human, animals and plant and can become a cause of various inflammatory pathologies while the patients with immune suppressed conditions, such as like postoperative patients, patients with transplanted organs, oncological diseases, AIDS, etc. In a majority of cases, the main percentage of infections are caused by Pseudomonas aeruginosa, Pseudomonas fluorescens and other representatives of this genus, as well as Stenotrophomonas maltophilia (former Pseudomonas maltophilia) (Katara et al., 2012, Marcelletti and Scortichini, 2014, Deredjian, et al. 2016, Lerminiaux and Cameron, 2019, Gale et al., 2015, Wong et al., 2011 Baumrin et. al, 2017). The main problem during the therapy of Pseudomonas infections is the multidrug resistance of these bacteria and the high adaptation potential of them to large spectrum of environmental changes. They are well-known by the abilities of various xenobiotics biodegradation (Moradali, 2017, Paras, 2015, Salam, 2016).

That is why the searching of new antibacterial alternatives against the pseudomonas different representatives carries a huge medical importance. Besides, being a very common inhabitants of wet surfaces in large diapason of temperature and $\mathrm{pH}$, these bacteria can be involved in numberless quantity of consumption chains and spread their native resistance to various Gramm-negative bacteria by the mobile genetical elements in gene horizontal transfer processes. That can led to new resistant strains forming, what has not only medical but also ecological negative consequences (Adegoke et al, 2017, Demanèche et al., 2001.).

Thus, the search of a comparably ecologically safe methods against these microorganisms is a very significant problem. One of the methods for combating against the multidrug resistant microorganisms are the natural organic acids of plants and their derivatives (Babayan, 2019).

Tartaric acid is a representative of aldaric acids of plant organisms. This substance is widely represented in different plants. Tartaric acid and the salts of it $(\mathrm{K}, \mathrm{Na}, \mathrm{Na} / \mathrm{K}, \mathrm{Ca}-$ tartrates) are being broadly used by mankind in different scoped of actions, including food industry (food additive E-334, etc) as preservatives which are safe for human organism (Eswaranandam et. al, 2004).

The main aim of current research was to test and compare the antibacterial effect of tartaric acid well-known and 4 new synthetic derivatives of tartaric acid (fig. 1), which were elaborated in National Polytechnic University of Armenia: benzylimide, cyclohexylimide, benzyl mono amino salt and Cyclohexyl mono amino salt of Tartaric acid. 
Figure 1: Tartaric acid synthetic derivatives: A -Benzylimide of tartaric acid, B - Cyclohexylimide of tartaric acid, $C$-Benzyl mono amino salt of tartaric acid, D-Cyclohexyl mono amino salt of tartaric acid.

A

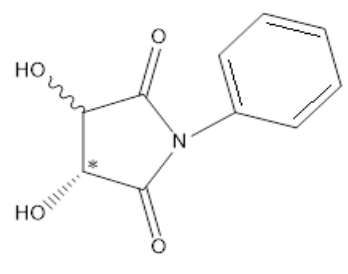

$\mathrm{C}$

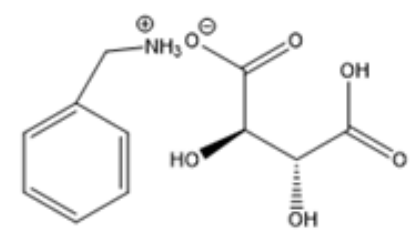

B
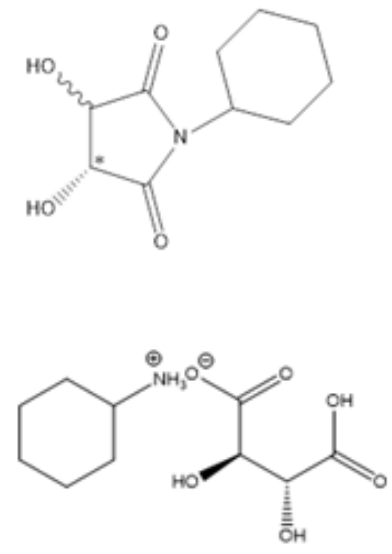

\section{Materials and Methods}

As the object there were used 49 strains of Pseudomonas fluorescens and other representatives of Pseudomonas from The National Microbe Collection of SPC "Armbiotechnology" NAS RA. The new derivatives of Tartaric acid were elaborated at the laboratory of New Agrochemical Creation at National Polytechnic University of Armenia (NPUA) from the natural source - the waste product of wine industry, cream of tartar (Dashchyan et al., 2014, Gharajyan et al., 2018). The antimicrobial resistance tests were done according to standard protocols (Babayan et al., 2019). DNA isolation was done by benzyl chloride and by alkaline extraction method and agarose gel electrophoresis. Transformation was done according to Mandel's method of competent cells obtaining with usage of $\mathrm{CaCl}_{2}$. Biodegradation tests were done according to standard protocols, by the substitution of carbon source in cultural media by the researched compounds (Delaney et al., 2018, Hen et al., 1993, Lucotte and Baney, 1993, Viovy, 2000, Singh et al., 2010).

\section{Results and Discussion}

The results of antimicrobial resistance of researched strains are represented on table 1.

During the experiments, 49 strains of Pseudomonas fluorescens were cultivated on media containing different classes of antibiotics of last generations: ceftriaxone of $\beta$-lactams, azithromycin of macrolides, ciprofloxacin of fluoroquinolones, chloramphenicol of amphenicoles and kanamycin of aminoglycosides. According to obtained data, the resistant, and especially multidrug resistant representatives are not in a majority of researched bacteria. The resistance to kanamycin was not detected. It's very important to note that all the researched strains are demonstrating the resistance even after the long-term cultivation on nutrient agar cultural media without any contact with antibiotics. Thus, the antibiotic resistance for all the researched bacteria is the stabile property.

Then all from all the researched strains total and plasmid DNA was isolated for the comparison of their genetical apparat. According to the obtained data, about $50 \%$ of these 
Strains were plasmid containing. Transformation analysis showed that not for all of them the plasmids are related with the resistance $(14 \%)$.

Table 1. Antibiotic resistance of P. fluorescens soil strains $(50 \mathrm{mkg} / \mathrm{ml})$ (Cro - Ceftriaxone, Kan Kanamycin, Cip - ciprofloxacin, Chl -chloramphenicol, azithromycin, C-control on nutrient agar cultural media, "+”-growth, “-"-the absence of growth).

\begin{tabular}{|c|c|c|c|c|c|c|c|c|c|c|c|c|c|}
\hline Strain & Cro & $\begin{array}{l}\mathrm{Ka} \\
\mathrm{n}\end{array}$ & Cip & Chl & Azm & $\mathrm{C}$ & Strain & Cro & $\begin{array}{l}\mathrm{Ka} \\
\mathrm{n}\end{array}$ & Cip & Chl & Azm & $\mathrm{C}$ \\
\hline 9120 & + & - & - & - & - & + & 9090 & + & - & - & - & + & + \\
\hline 9124 & + & - & - & - & - & + & 9131 & - & - & - & - & - & + \\
\hline 9098 & + & - & - & - & - & + & 9110 & + & - & - & - & - & + \\
\hline 9099 & - & - & - & - & - & + & 9111 & + & - & - & - & + & + \\
\hline 9134 & + & - & + & - & + & + & 9121 & + & - & - & - & - & + \\
\hline 9094 & - & - & - & - & - & + & 9114 & - & - & - & - & - & + \\
\hline 9140 & + & - & + & + & + & + & 9115 & + & - & - & - & - & + \\
\hline 9100 & - & - & - & - & - & + & 9070 & + & - & - & - & - & + \\
\hline 9205 & + & - & + & - & - & + & 9072 & + & - & - & - & + & + \\
\hline 9106 & - & - & - & - & - & + & 9077 & + & - & - & - & - & + \\
\hline 9108 & - & - & - & - & - & + & 9089 & + & - & - & - & + & + \\
\hline 9095 & + & - & - & - & + & + & 9069 & & - & - & - & - & + \\
\hline 9084 & + & - & + & - & - & + & 9068 & - & - & - & - & - & + \\
\hline 9123 & + & - & - & - & + & + & 9073 & _ & - & - & - & + & + \\
\hline 9096 & + & - & - & - & - & + & 9179 & + & - & - & - & - & + \\
\hline 9185 & + & - & + & - & - & + & 9107 & + & - & - & - & + & + \\
\hline 9085 & + & - & - & - & + & + & 9118 & + & - & + & - & - & + \\
\hline 9081 & + & - & + & - & - & + & 9120 & + & - & - & - & - & + \\
\hline 9091 & - & - & - & - & - & + & 9103 & - & - & - & - & + & + \\
\hline 9092 & + & - & + & - & + & + & 9142 & + & - & + & + & + & + \\
\hline 9127 & - & - & - & - & - & + & 9147 & + & - & + & - & + & + \\
\hline 9152 & - & - & - & - & - & + & 9149 & + & - & - & - & - & + \\
\hline 9128 & - & - & - & - & - & + & 9150 & - & - & - & - & - & + \\
\hline 9132 & + & - & + & - & + & + & 9153 & - & - & - & - & - & + \\
\hline 9143 & - & - & - & - & - & + & & & & & & & \\
\hline
\end{tabular}

Then all the researched strains were cultivated on media containing tartaric acid and the derivatives of it. The results are presented on table 2 . 
Table 2. The antibacterial effect of $T A$ derivatives $(50 \mathrm{mkg} / \mathrm{ml})$ of different representatives of Pseudomonas fluorescens (TA - tartaric acid, $K-K / N a$-tartrate, CI-cyclohexylimide of TA dissolved in DMSO, BI - benzylimide dissolved in DMSO, BAS - benzyl mono amino salt of TA, CAS - Cyclohexyl mono amino salt of TA; “+” - growth, “- “ - the absence of growth, * - late growth after III day, ** - late growth after IV day, *** late growth of singular colonies after $V$ day, $C$-control on nutrient solid agar media).

\begin{tabular}{|c|c|c|c|c|c|c|c|c|c|c|c|c|c|c|c|}
\hline Strain & BI & CI & BAS & CAS & $\begin{array}{l}\mathrm{T} \\
\mathrm{A}\end{array}$ & $\mathrm{K}$ & $\mathrm{C}$ & Strain & BI & CI & BAS & CAS & $\begin{array}{l}\mathrm{T} \\
\mathrm{A}\end{array}$ & $\mathrm{K}$ & $\mathrm{C}$ \\
\hline 9120 & - *** & - & -** & - & + & + & + & 9090 & + & $+^{*}$ & + & $+^{*}$ & + & + & + \\
\hline 9124 & - & + & - & - & + & + & + & 9131 & - & - & -*** & - & + & + & + \\
\hline 9098 & - & - & -*** & - & + & + & + & 9110 & - & - & - & - & + & + & + \\
\hline 9099 & + & - *** & $+* *$ & + & + & + & + & 9111 & + & + & + & + & + & + & + \\
\hline 9134 & + & + & + & + & + & + & + & 9121 & + & $\begin{array}{l}- \\
* * *\end{array}$ & -*** & $+^{*}$ & + & + & + \\
\hline 9094 & + & + & - $* * *$ & - & - & - & + & 9114 & $+* *$ & $\begin{array}{l}- \\
* * *\end{array}$ & -*** & ** & $+*$ & + & + \\
\hline 9140 & + & + & -*** & -*** & + & + & + & 9115 & - & - & - & - & $+*$ & + & + \\
\hline 9100 & $+*$ & - & - $* * *$ & -*** & + & + & + & 9070 & - & - & - & - & + & + & + \\
\hline 9205 & - & - & - & - & + & - & + & 9072 & - & -*** & - & -*** & + & + & + \\
\hline 9106 & - & - *** & - & - & $+^{*}$ & - & + & 9077 & -*** & - $* * *$ & -*** & -*** & - & - & + \\
\hline 9108 & + & + & + & + & + & + & + & 9089 & - & + & + & - & - & - & + \\
\hline 9095 & - **** & - & + & + & + & + & + & 9069 & - & $+* *$ & $+* *$ & - & + & - & + \\
\hline 9084 & - & $-* * *$ & -*** & -*** & + & - & + & 9068 & - & - & - & - & + & - & + \\
\hline 9123 & + & + & + & + & + & + & + & 9073 & + & + & + & + & + & + & + \\
\hline 9096 & + & -***. & + & $+* *$ & + & - & + & 9179 & + & + & - & - & + & + & + \\
\hline 9185 & + & + & + & + & + & + & + & 9107 & + & + & - & - & + & + & + \\
\hline 9085 & + & + & - & - & + & + & + & 9118 & $+* *$ & -*** & $+* *$ & -*** & $t^{*}$ & + & + \\
\hline 9081 & - & $+*$ & - *** & - & - & + & + & 9120 & $+^{*}$ & + & $+* * *$ & + & $+*$ & + & + \\
\hline 9091 & - & $+* *$ & $-* * *$ & - & $+*$ & + & + & 9103 & $+* * *$ & + & $+* * *$ & + & - & + & + \\
\hline 9092 & - & $+^{*}$ & $-* * *$ & - & $+^{*}$ & + & + & 9142 & - & - & - & - & - & - & + \\
\hline 9127 & + & + & + & - $* * *$ & + & + & + & 9147 & $+* *$ & $+* *$ & $+*$ & $+* *$ & $+*$ & + & + \\
\hline 9152 & - & $+*$ & $+*$ & + & + & + & + & 9149 & + & + & - & - & $+*$ & + & + \\
\hline 9128 & $+^{*}$ & + & + & $+^{*}$ & + & + & + & 9150 & -*** & -*** & - & - & $+^{*}$ & + & + \\
\hline 9132 & $+*$ & + & $+^{*}$ & -*** & + & + & + & 9153 & - $* * *$ & $-* * *$ & - & - $* * *$ & $+*$ & + & + \\
\hline \multirow[t]{2}{*}{ Strain } & \multirow[t]{2}{*}{ BI } & \multirow[t]{2}{*}{ CI } & \multirow[t]{2}{*}{ BAS } & \multirow[t]{2}{*}{ CAS } & \multirow{2}{*}{$\begin{array}{l}\mathrm{T} \\
\mathrm{A}\end{array}$} & \multirow[t]{2}{*}{$\mathrm{K}$} & + & 9143 & - & -** & - & $-* * *$ & - & + & + \\
\hline & & & & & & & C & Strain & BI & CI & BAS & CAS & $\begin{array}{l}\mathrm{T} \\
\mathrm{A}\end{array}$ & K & $\mathrm{C}$ \\
\hline
\end{tabular}


According to the presented data, in a majority of cases, the effect of researched compounds is being presented by both bacteriostatic (with the prolongation of growth period) and bactericide (the absence of growth even after 7 days of cultivation) activities. Besides, in some strains it's notable the forming of singular resistant colonies after few days of cultivation. Probably it is caused by selection of resistant mutants. Probably it is related with polyphenol oxidase activity of Pseudomonas (Taranto et al, 2017). Then the resistant strains were cultivated on mineral media for biodegradation tests.

The results showed that biodegradation of salts processes more intensively. Probably it is caused by their more hydrophilic properties, in opposite to hydrophobic imides. On a next stage, there were done transformation of sensitive strains of $P$. aeruginosa 9056 by the plasmid DNA of these resistant strains. Thus, during the experiments there were not detected transformants, with the resistance to tartaric acid derivatives or ability to biodegradation of them on mineral media.

\section{Conclusion}

During all the experiments with tartaric acid benzyl- and cyclohexyl- imides as well as benzyl- and cyclohexyl- mono amino salts of it on 49 native soil strains of Pseudomonas fluorescens, the antibacterial effect was detected for all 4 compounds. They are effective as antibacterial agents against both sensitive and multidrug resistant strains of researched Pseudomonas fluorescens. That effect in a majority of cases was stronger than in case of wellknown tartaric acid derivatives usage. In some strains the effect was presented by prolongation of growth till 1-2 days.

In other part of Pseudomonas fluorescens representatives there were detected single colonies which were resistant to all tested compounds. Probably they were mutated by their bacterial chromosome genes. That mutations are not transmittable by plasmids in plasmid containing strains. Probably, these mutations are related with genes of polyphenol oxidases, which are presented in genome of Pseudomonas.

During the tests of biodegradation, cyclohexyl- derivatives showed less biodegradative properties than benzyl-derivatives. Probably it is caused by cyclohexyl radical chemical structure features and disabilities of bacterial enzymes to recognize these molecules as substrates. Soil opportunistic pathogenic strains of Pseudomonas can be a good models of highly adaptive pathogenic bacteria. Thus, all the tested semisynthetic substances are recommended for further research of their efficiency as antibacterial agents and ecological safeness, as potentially biodegradative compounds.

\section{Acknowledgment}

This paper is an output of the science projects, which were supported by RA MES State Committee of Science, in the frames of the research project № 15Ap_2e016 and research grant from the Armenian National Science and Education Fund (ANSEF) based in New York, USA, Grant No microbio-5133. 


\section{References}

[1] Katara P, Grover A and Sharma V. (2012). "In silico prediction of drug targets in phytopathogenic Pseudomonas syringae pv. phaseolicola: charting a course for agrigenomics translation research," OMICS. 16(12) pp700-706.

[2] Marcelletti S and Scortichini M. (2014). "Definition of Plant-Pathogenic Pseudomonas genomospecies of the Pseudomonas syringae Complex Through Multiple Comparative Approaches,”, Phytopathology, 104(12) pp. 1274-82.

[3] Deredjian A., Alliot N, Blanchard L, Brothier E, Anane M, Cambier P, Jolivet C, Khelil M.N., Nazaret S., Saby N., Thioulouse J. and Favre-Bonté S. (2016), "Occurrence of Stenotrophomonas maltophilia in agricultural soils and antibiotic resistance properties," Res Microbiol., 167(4): pp.313-324.

[3] Lerminiaux N.A. and Cameron A.D.S. (2019). "Horizontal transfer of antibiotic resistance genes in clinical environments," Can J Microbiol., 65(1): pp.34-44.

[4] Gale M.J., Maritato M.S., Chen Y.L., Abdulateef S.S. and Ruiz J.E.. (2015). "Pseudomonas aeruginosa causing inflammatory mass of the nasopharynx in an immunocompromised HIV infected patient: A mimic of malignancy, " IDCases 11;2(2): pp. 4043.

[5] Wong V, Levi K, Baddal B, Turton J and Boswell T.C, (2011). "Spread of Pseudomonas fluorescens due to contaminated drinking water in a bone marrow transplant unit, J Clin Microbiol., 49(6): pp. 2093-2096.

[6] Moradali F.M., Ghods Sh., and Rehm B.H.A., (2017). "Pseudomonas aeruginosa Lifestyle: A Paradigm for Adaptation, Survival, and Persistence,|Front Cell Infect Microbiol, 7: pp. 39.

[7] Baumrin E, Piette E.W. and Micheletti R.G (2017). "Stenotrophomonas maltophilia: an emerging multi-drug resistant opportunistic pathogen in the immunocompromised host," $B M J$ Case Rep. pp. 221053.

[8] Paras J. (2015). "Xenobiotic Degradation by Bacterial Enzymes. Int. J. of Current Microbiol \& Appl. Science., 4. pp. 48-62. 
[9] Salam L.B. (2016). "Metabolism of waste engine oil by Pseudomonas species," 3 Springer, 3 Biotech, pp.6:98,

[10] Adegoke A.A., Stenström Th.A., Okoh A.I., (2017). "Stenotrophomonas maltophilia as an Emerging Ubiquitous Pathogen: Looking Beyond Contemporary Antibiotic Therapy," Front Microbiol., 8: pp. 2276

[11] Demanèche S., Kay E., Gourbière F. and Simonet P., (2001). "Natural Transformation of Pseudomonas fluorescens and Agrobacterium tumefaciens in Soil, "Appl Environ Microbiol. 67(6): pp. 2617-2621.

[12] Babayan B., (2019). “The Plasmid Differences In Multi-Drug Resistant Opportunistic Pathogenic Soil Strains of Pseudomonas and Stenotrophomonas," European Journal of Medicine and Natural Sciences (EJMN), V3, No 1, pp. 23-28.

[13] Eswaranandam S,. Hettiarachchy N. S., and Johnson M. G. (2004). “Antimicrobial Activity of Citric, Lactic, Malic, or Tartaric Acids and Nisin- incorporated Soy Protein Film Against Listeria monocytogenes, Escherichia coli O157:H7, and Salmonella gaminara," Journal of Food Science, 69(3), pp. FMS79-FMS84

[14] Dashchyan N.A., Asatryan N.L., Galstyan G.F. and Mikaelyan A.R. (2014). “Obtaining Bioactive Additives of Cyclic Structure on the Basis of Optically Active Tartaric Acid," Bulletin of NPUA, Collection of scientific papers, part II, pp. 682-68CLSI,

[15] Gharajyan S.K, Babayan B.G., Sogomonyan T.M., Mikaelyan A. R, Melkumyan M.A. and Baghdasaryan A. S. (2018). "The Influence of Tartaric Acid and The Derivatives of It On Some Soil Non Pathogenic Strains of Pseudomonas," The materials of Conference: "The Assessment of Biodiversity and Agro-Biodiversity Capacity of the RA and the Implementation of the Scientific-Educational Foundation for Biodiversity Conservation", ASPU, Yerevan, RA, 1(1), pp. 171-174

[16] Babayan B.G., Hovhannisyan N.A., Hovhannisyan A.M., Sargsyan A.S., Davidyan T.S. (2019). "Resistance To $\beta$-Lactam Antibiotics In Some Soil Stenotrophomonas and Pseudomonas," The Scientific-Heritage, V-2-No-34-2019, pp.32-38 
2nd International Conference on Research in

\section{SCIENCE, ENGINEERING \& TECHNOLOGY}

\section{Oxford, United Kingdom}

8-10 November 2019

[17] S. Delaney, R. Murphy and F. Walsh (2018). "A Comparison of Methods for the Extraction of Plasmids Capable of Conferring Antibiotic Resistance in a Human Pathogen From Complex Broiler Cecal Samples," Front Microbiol. 9: pp.1731

[18] Heng Zhu, Feng Qu and Li-Huang Zhu. (1993). "Isolation of Genomic DNA From Plants, Fungi and Bacteria Using Benzyl Chloride”. Nucleic Acid Research, 21 (22), pp.52795280 .

[19] Lucotte G. and Baneyx F. (1993). "Introduction to Molecular Cloning Techniques," Wiley-Blackwell, ISBN 978-0471188490. pp. 32..

[20] Viovy J.-L. (2000). "Electrophoresis of DNA and other polyelectrolytes: Physical mechanisms," Reviews of Modern Physics. 72: pp. 813-872.

[21] Singh M., Yadav A., Ma X. and Amoah E. (2010). "Plasmid DNA Transformation in Escherichia Coli: Effect of Heat Shock Temperature, Duration and Cold Incubation of $\mathrm{CaCl}_{2}$ Treated Cells," International Journal of Biotechnology and Biochemistry, 6 (4), pp. 561-568

[22] Taranto F., Pasqualone A., Mangini G., Tripodi P., Miazzi M.M., Pavan S. and Montemurro C. (2017). "Polyphenol Oxidases in Crops: Biochemical, Physiological and Genetic Aspects," Int J Mol Sci., 18(2): pp. 377. 